\title{
Influence of gold nanoparticle surface chemistry and diameter upon Alzheimer's disease amyloid- $\beta$ protein aggregation
}

Kelly A. Moore ${ }^{1}$, Kayla M. Pate ${ }^{2}$, Deborah D. Soto-Ortega ${ }^{1}$, Samuel Lohse ${ }^{5}$, Nicholas van der Munnik², Mihyun Lim³, Kaliah S. Jackson ${ }^{4}$, Venetia D. Lyles ${ }^{4}$, Lemeisha Jones ${ }^{4}$, Nisha Glassgow ${ }^{4}$, Vanessa M. Napumecheno ${ }^{4}$, Shanee Mobley ${ }^{4}$, Mark J. Uline ${ }^{1,2}$, Rahina Mahtab ${ }^{4}$, Catherine J. Murphy ${ }^{5}$ and Melissa A. Moss ${ }^{1,2^{*}}$

\begin{abstract}
Background: Deposits of aggregated amyloid- $\beta$ protein $(A \beta)$ are a pathological hallmark of Alzheimer's disease (AD). Thus, one therapeutic strategy is to eliminate these deposits by halting $A \beta$ aggregation. While a variety of possible aggregation inhibitors have been explored, only nanoparticles (NPs) exhibit promise at low substoichiometric ratios. With tunable size, shape, and surface properties, NPs present an ideal platform for rationally designed $A \beta$ aggregation inhibitors. In this study, we characterized the inhibitory capabilities of gold nanospheres exhibiting different surface coatings and diameters.

Results: Both NP diameter and surface chemistry were found to modulate the extent of aggregation, while NP electric charge influenced aggregate morphology. Notably, $8 \mathrm{~nm}$ and $18 \mathrm{~nm}$ poly(acrylic acid)-coated NPs abrogated $A \beta$ aggregation at a substoichiometric ratio of 1:2,000,000. Theoretical calculations suggest that this low stoichiometry could arise from altered solution conditions near the NP surface. Specifically, local solution pH and charge density are congruent with conditions that influence aggregation.

Conclusions: These findings demonstrate the potential of surface-coated gold nanospheres to serve as tunable therapeutic agents for the inhibition of A $\beta$ aggregation. Insights gained into the physiochemical properties of effective NP inhibitors will inform future rational design of effective NP-based therapeutics for AD.
\end{abstract}

Keywords: Alzheimer's disease, Amyloid- $\beta$ protein, Protein aggregation, Inhibition, Gold nanoparticles, Aggregate morphology

\section{Background}

In 1901, Alois Alzheimer examined a patient experiencing multiple neurological symptoms, including pronounced memory loss [1], marking the first diagnosis of what is now the most common neurodegenerative disorder, Alzheimer's disease (AD). Amyloid plaques, comprised of aggregated amyloid- $\beta(A \beta)$ protein [2] and found throughout the cerebral cortex [1], are a pathological hallmark of $\mathrm{AD}$. While monomeric $\mathrm{A} \beta$ is inert [3], $\mathrm{A} \beta$ aggregates induce neurotoxicity [4], inhibit neuronal long-term

\footnotetext{
*Correspondence: mossme@cec.sc.edu

'Biomedical Engineering Program, University of South Carolina, Columbia, SC 29208, USA

${ }^{2}$ Department of Chemical Engineering, University of South Carolina, 2C02

Swearingen Engineering Center, Columbia, SC 29208, USA

Full list of author information is available at the end of the article
}

potentiation [5-7], induce synapse loss [8], and disrupt memory and complex learned behavior [9]. As a result, halting $A \beta$ aggregation is one promising therapeutic strategy for AD. However, extensive investigation of small molecules and peptides as inhibitors of $\mathrm{A} \beta$ aggregation has failed to yield a successful therapeutic, necessitating the exploration of novel therapeutic agents.

Nanoparticles (NPs) have emerged as attractive therapeutic and diagnostic tools with applications in medical imaging, analytics, and drug delivery [10-14]. NPs can be synthesized from a wide range of materials including metals, polymers, and carbon-based molecules [11-14]. Furthermore, the ease with which NP size, shape, and surface properties are controlled [10-14] render NPs an ideal tunable platform for therapeutic applications. 
Among the growing body of potential therapeutic applications for NPs is their ability to modulate amyloid protein aggregation [15-19]. Inhibition of $A \beta$ aggregation, specifically, has been reported for NPs ranging in size from $<10 \mathrm{~nm}$ to several hundred nanometers and exhibiting diverse surface chemistries [20-28]. Moreover, these effects have been observed at picomolar NP concentrations and substoichiometric ratios of NP to protein. While a wide array of small molecules and peptides can disrupt $A \beta$ aggregation $[29,30]$, none have been as effective as NPs at substoichiometric ratios, thus increasing their potential for delivery of therapeutically effective concentrations to the brain. However, variations in NP size and surface chemistry can result in the contrasting promotion of $A \beta$ aggregation [21, 23, 24, 31-33]. Thus, there exists a need to better understand the impact of NP physiochemical properties upon $A \beta$ aggregation.

Using spherical NPs that vary in surface coating and size, this study investigates the effect that NP surface chemistry, charge, and diameter have upon $A \beta$ aggregation. Gold was selected as the NP core material because gold NPs are readily synthesized, easily functionalized, and highly stable against oxidative dissolution [34-36]. Examination of four NP surface chemistries as well as three different NP diameters revealed that electric charge, surface chemistry, and size all modulate the ability of gold nanospheres to inhibit $\mathrm{A} \beta$ aggregation. While NP diameter and surface chemistry impact the extent of inhibition, electric charge determines the ability to influence aggregate morphology. In particular, smaller, anionic NPs are superior inhibitors, halting aggregation at substoichiometric ratios as low as 1:2,000,000 with the protein. Theoretical calculations suggest that such low stoichiometry may be achieved through NP-induced alterations to local solution conditions, including $\mathrm{pH}$ and charge density. Together, these findings identify surface-coated gold NPs as potential therapeutic agents for AD and provide insight into the physiochemical properties displayed by NPs that effectively inhibit $A \beta$ aggregation.

\section{Results and discussion}

As part of the emergence of NPs in medical applications, development of NPs as inhibitors of amyloid protein aggregation has garnered attention [15-19]. With the ability to vary NP physiochemical properties, including material, size, and charge, NPs offer a tunable platform to modulate amyloid protein aggregation [37, 38]. However, the influence of NP characteristics on protein aggregation is poorly understood [15-17]. This study characterizes the inhibition of $A \beta$ aggregation by gold nanospheres with varying surface chemistry and diameter. A cellular assay was used to probe the neurotoxicity of synthesized NPs, while a fluorescent amyloid-binding dye and transmission electron microscopy (TEM) were employed to characterize NP-induced alterations in A $\beta$ aggregate formation and morphology, respectively. These investigations define a role for NP size, electric charge, and surface chemistry in determining inhibitory capabilities, and a theoretical model provides insight into the possible mechanism of inhibition.

\section{Toxicity of surface-coated gold NPs}

Toxicity of gold NPs is dependent upon their size, shape, and surface coating [39-43]. To probe the biocompatibility of synthesized NPs as therapeutic agents, their potential to elicit a toxic response was evaluated within human neuroblastoma SH-SY5Y cells, a widely used model for the study of prospective AD therapeutics. Following $24 \mathrm{~h}$ exposure of SH-SY5Y cells to surfacecoated NPs, cellular metabolic activity was assessed using 2,3-bis(2-methoxy-4-nitro-5-sulfophenyl)-2H-tetrazolium5-carboxanilide (XTT) reduction. At NP concentrations of $100 \mathrm{pM}$ and $200 \mathrm{pM}$, cellular viability remained $>95 \%$ following incubation with $18 \mathrm{~nm}$ NPs displaying citrate, poly(acrylic acid) (PAA), or polyelectrolytes poly(allylamine)hydrochloride (PAH) surface chemistries (Fig. 1a). In contrast, $18 \mathrm{~nm}$ cetyltrimethylammonium bromide (CTAB) coated NPs reduced cellular viability to less than $20 \%$, a viability level comparable to cells treated with $2 \%$ Triton-X, thus indicating their propensity to induce toxicity. This result is congruent with observations that CTAB-coated nanoparticles are toxic toward other cell types [39-41], while their further overcoating reduces the toxic effects [39, 41]. When cells were incubated in the presence of PAA-coated NPs of varying size, NPs $8 \mathrm{~nm}$ and $18 \mathrm{~nm}$ in diameter did not elicit toxicity. In contrast, $40 \mathrm{~nm}$ PAA-coated NPs were toxic, with both $100 \mathrm{pM}$ and $200 \mathrm{pM}$ NPs reducing cellular viability to less than $10 \%$ (Fig. 1b). Similarly, other studies have shown sizedependent toxicity for nanoparticles, with larger sizes eliciting a more toxic response [42, 43]. Results here demonstrate that NP toxicity toward SH-SY5Y cells is influenced by both surface chemistry and size and that several NPs considered in the current study are inert in SH-SY5Y cultures.

\section{Effect of surface-coated gold NPs on ThT fluorescence detection of $A \beta_{1-40}$ aggregates}

The plasmonic nature of NPs imparts an ability to absorb and scatter light, which may enhance or quench fluorescent signals [44]. This property presents the possibility that NPs could alter fluorescence of thioflavin T (ThT), which binds the $\beta$-sheet structure characteristic of fibrillar $A \beta$ aggregates to yield a shifted, enhanced fluorescence and is thus commonly used to monitor the progression of aggregation. To ensure that observed differences in ThT fluorescence accurately reflect changes in $\mathrm{A} \beta$ aggregate formation, ThT fluorescence was assessed 


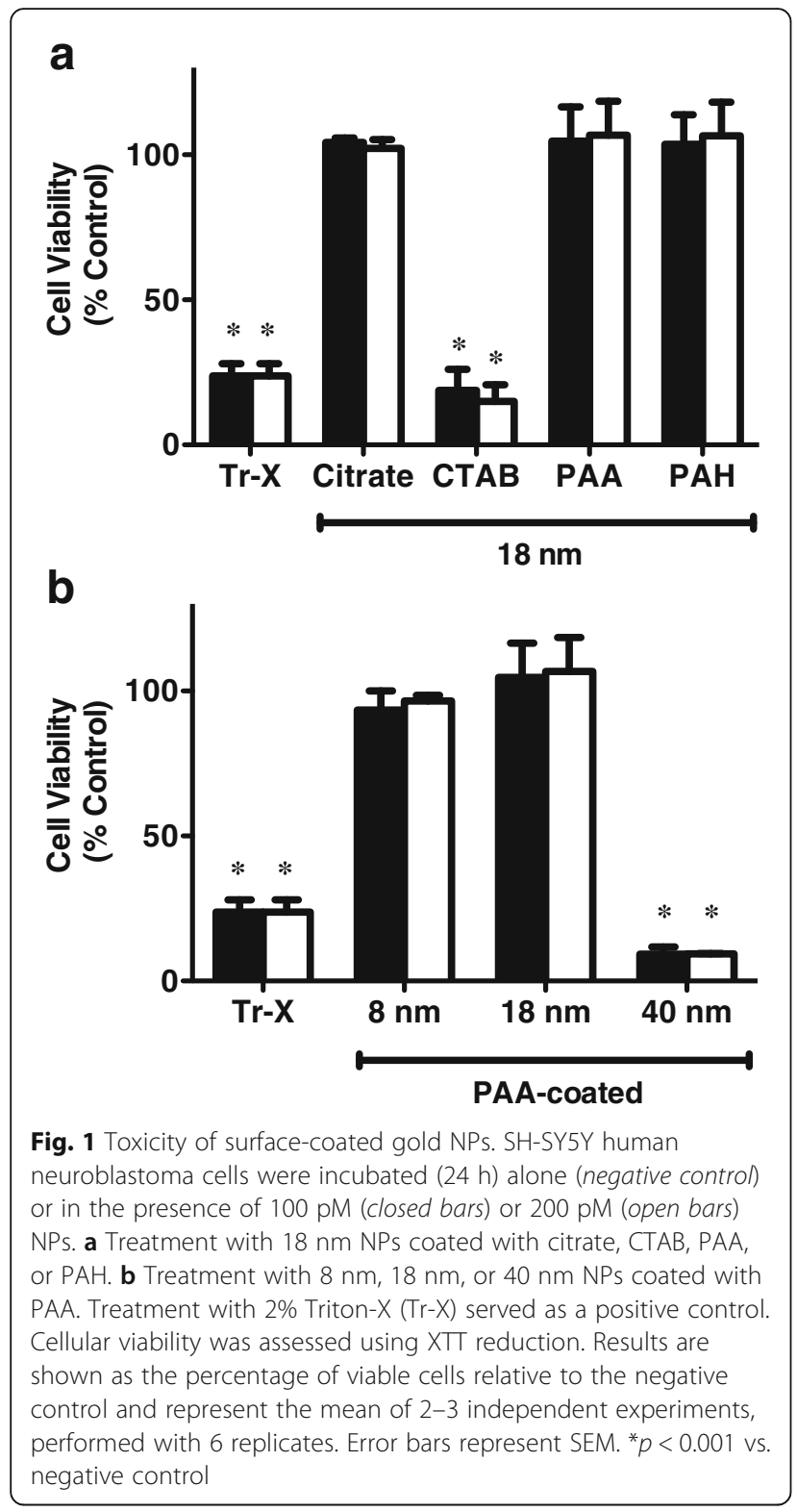

for $5 \mu \mathrm{M}$ pre-formed fibrillar $A \beta_{1-40}$ aggregates incubated for $2 \mathrm{~h}$ in the absence (control) or presence of 5-200 pM surface-coated NPs. These concentrations are representative of diluted solutions used for monitoring aggregation. Among $18 \mathrm{~nm}$ NPs, ThT fluorescence detection of A $\beta_{1-40}$ fibrils was unaltered by NPs displaying citrate, PAA, and PAH surface chemistries (Fig. 2a). In contrast, CTABcoated NPs significantly quenched ThT fluorescence detection of aggregated $A \beta_{1-40}$ at concentrations of $50 \mathrm{pM}$ and higher. When PAA-coated NPs of varying diameter were compared, neither $8 \mathrm{~nm}$ nor $18 \mathrm{~nm}$ NPs altered the detection of $\mathrm{A} \beta_{1-40}$ fibrils by ThT; however, ThT fluorescence detection was again significantly quenched by the presence of $40 \mathrm{~nm}$ PAA-coated NPs (Fig. 2b). Other studies have shown that small molecule inhibitors of $A \beta$

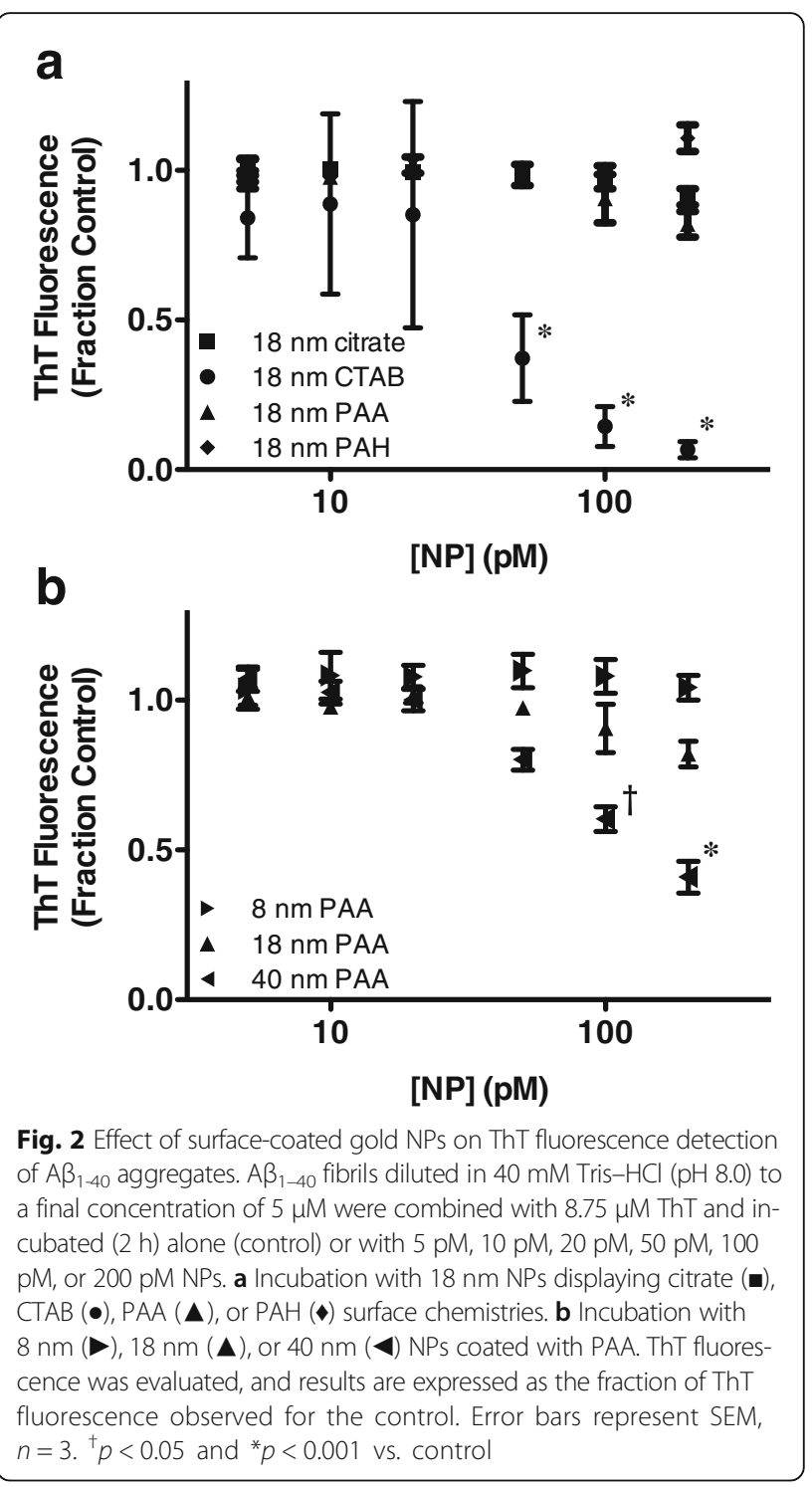

aggregation can also reduce ThT fluorescence detection of $\mathrm{A} \beta$ aggregates, although via a different mechanism of binding competition $[45,46]$. These studies advocate caution toward the unmitigated use of ThT fluorescence to study $A \beta$ aggregation inhibitors. As a result, assessment of the effect of $18 \mathrm{~nm}$ CTAB-coated NPs and $40 \mathrm{~nm}$ PAAcoated NPs was limited to TEM analysis.

$18 \mathrm{~nm}$ surface-coated gold NPs inhibit $A \beta_{1-40}$ monomer aggregation and alter fibril morphology

The effect of synthesized NPs on $A \beta$ aggregation was evaluated using $A \beta_{1-40}$, the most abundant monomeric isoform in vivo [47] as well as the dominant species found in amyloid plaques [48]. Aggregation of $40 \mu \mathrm{M}$ monomeric protein was stimulated by continuous agitation, and ThT fluorescence was used to monitor the formation of $\beta$-sheet amyloid aggregates. $A \beta_{1-40}$ 
aggregation yielded a characteristic growth pattern displaying an initial lag phase, indicative of nucleation, which was followed by rapid aggregate growth that ceased at equilibrium, as evidenced by plateau of the fluorescence signal (Fig. 3a). Inhibition of $A \beta_{1-40}$ aggregation by NPs was quantified via changes in the lag time and equilibrium plateau. Extension of the lag time occurs early in aggregation and is indicative of an increased time to nucleation. Lag extension was calculated as a fold-change, relative to the control, in the time at which ThT fluorescence first increases. Reduction of the plateau fluorescence is evidenced at equilibrium and indicates a decrease in the total quantity of aggregates containing $\beta$-sheet structure. Plateau

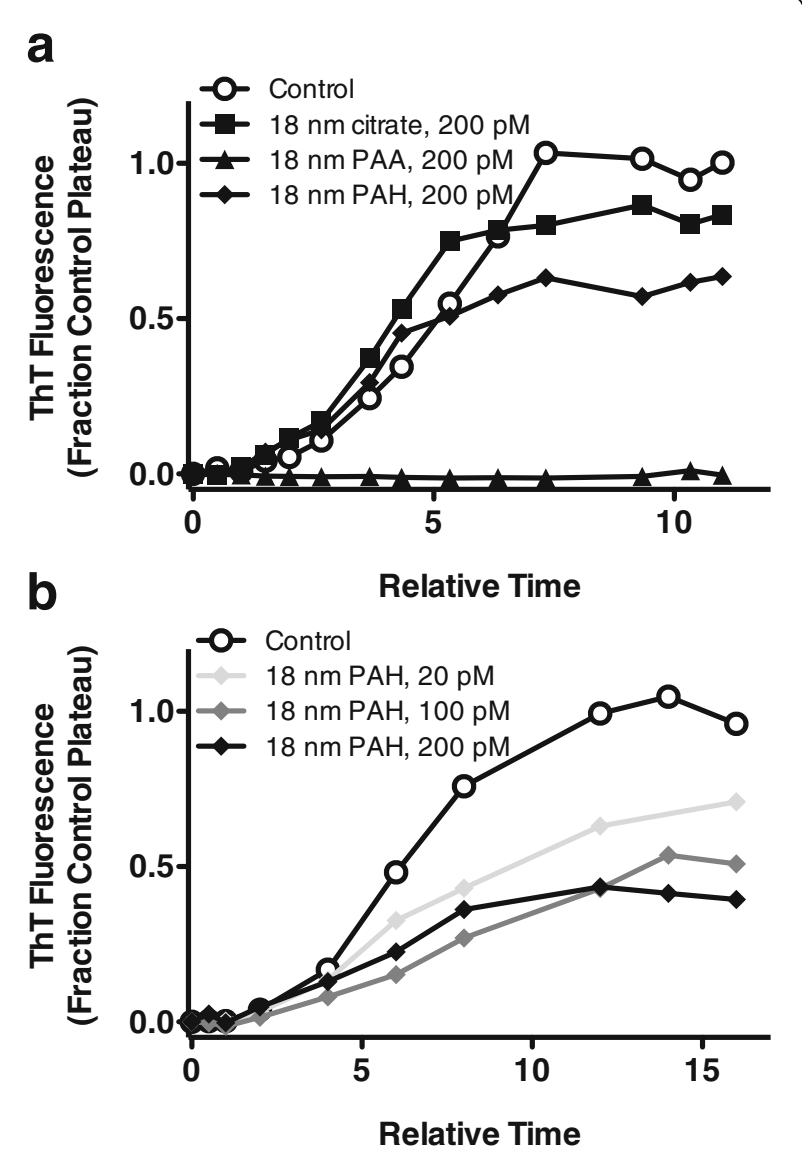

Fig. 3 Effect of $18 \mathrm{~nm}$ surface-coated gold NPs on $A \beta_{1-40}$ monomer aggregation. $\mathrm{A} \beta_{1-40}$ monomer diluted to $40 \mu \mathrm{M}$ in $40 \mathrm{mM}$ Tris- $\mathrm{HCl}$ ( $\mathrm{pH}$ 8.0) was aggregated alone (control, O) or in the presence of surface-coated NPs. a Aggregation in the presence of 200 pM NPs displaying citrate $(\mathbf{\bullet})$, PAA $(\boldsymbol{\Delta})$, or PAH $(\bullet)$ surface chemistries. b Aggregation in the presence of $200 \mathrm{pM}(\downarrow), 100 \mathrm{pM}(\diamond)$, or 20 pM ( ) PAH-coated NPs. Monomer aggregation was induced by continuous agitation and monitored periodically via ThT fluorescence. ThT fluorescence, expressed as the fraction of the control equilibrium plateau, is plotted versus relative time, which is the fraction of the control lag time. Results are representative of 3-5 independent experiments reduction was calculated as the percentage decrease in ThT fluorescence at equilibrium.

When monomer aggregation was stimulated in the presence of NPs, none of the NPs were capable of delaying nucleation to extend the lag time. However, at 200 pM several NPs did decrease the quantity of $\beta$-sheet aggregates formed at equilibrium (Fig. 3a). Aggregates formed in the presence of $200 \mathrm{pM}$ citrate- or PAH-coated NPs exhibited a $19 \pm 8 \%$ and $59 \pm 9 \%$ reduction of the equilibrium plateau, respectively (Table 1 ). The most pronounced effect was observed with PAA-coated NPs, which completely abrogated aggregation. Inhibition of $A \beta_{1-40}$ aggregation by surface-coated NPs was also observed to be dose dependent (Table 1). Inhibition by PAH-coated NPs decreased from nearly $60 \%$ at a concentration of $200 \mathrm{pM}$ to less than $45 \%$ at a concentration of $20 \mathrm{pM}$ (Fig. 3b, Table 1), and citrate-coated NPs were ineffective at concentrations below 200 pM (Table 1). PAA-coated NPs, however, continued to fully abrogate inhibition at concentrations as low as $20 \mathrm{pM}$, or a 1:2,000,000 substoichiometric ratio of NPs to $A \beta_{1-40}$ (Table 1). To ensure these inhibitory effects were characteristic of the NPs and not just surface coatings, monomer aggregation was also performed in the presence of $100 \mu \mathrm{M}$ solubilized sodium citrate, CTAB, PAA, or PAH; each failed to elicit any inhibitory effect (results not shown).

To confirm inhibition of $A \beta_{1-40}$ aggregation by synthesized NPs as well as to further investigate changes in aggregate morphology, TEM images were acquired following a time point after which aggregation reactions had reached equilibrium. Aggregates formed in the absence of NPs exhibit a network of filamentous fibrils comprised of single or multiple strands (Fig. 4a, d). This morphology is in agreement with other studies of $A \beta$ aggregation [20, 24, 27, 33].

When $A \beta_{1-40}$ aggregates were formed in the presence of 200 pM citrate-coated (Fig. 4b) or PAH-coated (Fig. 4c) NPs, the quantity of aggregates was reduced compared to the control. These results corroborate the plateau reductions observed via ThT fluorescence. TEM additionally facilitated examination of the influence of CTAB-coated

Table 1 Percent inhibition of $A \beta_{1-40}$ monomer aggregation observed in the presence of surface-coated NPs ${ }^{a, b}$

\begin{tabular}{llllll}
\hline NP type & & & {$[N P]$} & & \\
\cline { 1 - 2 } \cline { 6 - 7 } Surface Modification & Diameter & & $20 \mathrm{pM}$ & $100 \mathrm{pM}$ & $200 \mathrm{pM}$ \\
\hline Citrate & $18 \mathrm{~nm}$ & & $4.3 \pm 2.6$ & $0.0 \pm 0.0$ & $19 \pm 8^{*}$ \\
PAH & $18 \mathrm{~nm}$ & & $45 \pm 4^{*}$ & $47 \pm 5^{*}$ & $59 \pm 9^{*}$ \\
PAA & $18 \mathrm{~nm}$ & & $97 \pm 2^{*}$ & $99 \pm 0^{*}$ & $95 \pm 3^{*}$ \\
PAA & $8 \mathrm{~nm}$ & & $95 \pm 3^{*}$ & $92 \pm 4^{*}$ & $94 \pm 1^{*}$ \\
\hline
\end{tabular}

${ }^{*} p<0.001$ compared to control

anhibition is expressed as plateau reduction, or the percentage of reduction in the equilibrium plateau compared to the control

${ }^{\mathrm{b}}$ Parameters are expressed as mean $\pm \mathrm{SEM}, n=3-5$ 

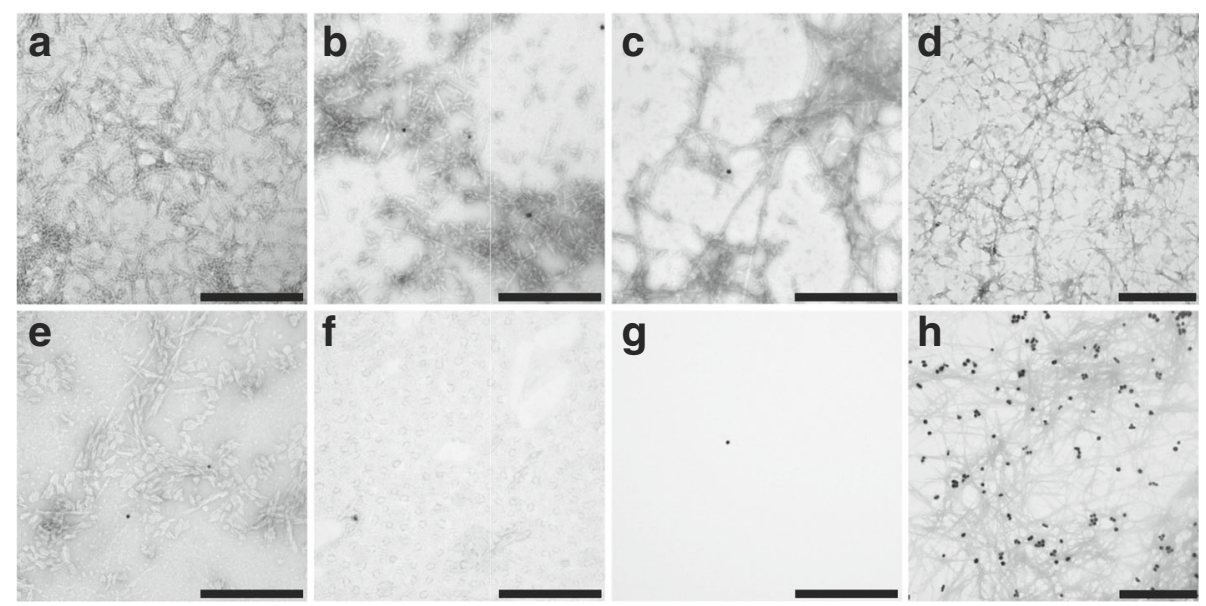

Fig. 4 Effect of surface-coated gold NPs with different surface coatings and diameters on $A \beta_{1-40}$ aggregate morphology. $A \beta_{1-40}$ monomer diluted to $40 \mu \mathrm{M}$ in $40 \mathrm{mM}$ Tris- $\mathrm{HCl}$ (pH 8.0) was aggregated alone (control, panels $\mathbf{a}$, d) or in the presence of $200 \mathrm{pM}$ citrate-coated (panel b), PAH-coated (panel c), CTAB-coated (panel e), or PAA-coated (panel g) NPs $18 \mathrm{~nm}$ in diameter. Additionally, monomer was aggregated in the presence of $200 \mathrm{pM}$ PAA-coated NPs exhibiting diameters of $8 \mathrm{~nm}$ (panel $\mathbf{f}$ ) or $40 \mathrm{~nm}$ (panel $\mathbf{h}$ ). Monomer aggregation was induced by continuous agitation, and the control reaction was monitored periodically via ThT fluorescence. Upon evidence of equilibrium, samples were gridded and visualized by TEM. Results are representative of 2 independent experiments. Images are shown relative to a scale bar of $500 \mathrm{~nm}$ at 100,000x (panels $\mathbf{a}-\mathbf{c}, \mathbf{e}-\mathbf{g}$ ) or 75,000x (panels $\mathbf{d}, \mathbf{h}$ ) magnification

NPs on $A \beta_{1-40}$ aggregation, for which analysis by ThT fluorescence was precluded. Aggregates formed in the presence of 200 pM CTAB-coated NPs exhibited a reduction in aggregate quantity (Fig. 4e), demonstrating that these NPs can also inhibit $A \beta_{1-40}$ aggregation. When $A \beta_{1-40}$ aggregation was stimulated in the presence of $200 \mathrm{pM} 18 \mathrm{~nm}$ PAA-coated NPs, an absence of filamentous aggregates was observed (Fig. 4g), substantiating the ability of these NPs to abrogate aggregation. Together, TEM results confirm the relative inhibitory capabilities of surface-coated NPs observed by ThT fluorescence as well as the complete inhibition imparted by PAA-coated NPs.

While the most effective inhibitors were NPs coated with anionic PAA, NPs exhibiting both negative and positive surface charges inhibited $A \beta$ aggregation. This observation agrees with previous studies that have described both anionic and cationic NPs as inhibitors of protein aggregation [20, 21, 23-25, 28, 49-55]. Among the NPs examined within the current study, however, those with anionic citrate and PAA coatings were more effective inhibitors than those with cationic $C T A B$ and PAH coatings. This finding aligns with other studies that have observed superior inhibitory capabilities by anionic NPs over cationic NPs [20, 21, 23, 25, 28]. Among anionic NPs, PAA-coated particles exhibited superior inhibitory capabilities over citrate-coated particles. Other studies also report variances in inhibition of amyloid protein aggregation by NPs displaying different surface chemistries with the same electric charge [22, 25]. In comparison to monomeric citrate, polymeric PAA will exhibit molecular reorganization transitions with the local solution environment [56]. These transitions can result in spatially dependent changes to physical parameters that may facilitate inhibition, as discussed in the next section.

TEM images further revealed that NPs with different coatings exert different effects on aggregate morphology. While aggregates formed in the presence of anionic citrate-coated NPs exhibited a morphology similar to the control (Fig. 4b), aggregates formed in the presence of cationic NPs demonstrated altered morphologies. PAHcoated NPs induced the formation of an increased number of thin, elongated aggregate structures (Fig. 4c), while CTAB-coated NPs induced the formation of short, thick associated aggregates (Fig. 4e). Thus, these results demonstrate the ability of cationic, but not anionic, NPs to influence aggregate morphology. Other studies have described similar NP-induced changes in aggregate structure, with a diverse array of morphologies reported $[20,21,26,49,50,52,54,55]$. However, these observations are not confined to cationic NPs.

\section{NP size influences inhibition of $A \beta_{1-40}$ monomer aggregation by PAA-coated gold NPs}

The complete inhibition of $A \beta_{1-40}$ aggregation observed in the presence of $18 \mathrm{~nm}$ PAA-coated NPs prompted further experimentation to elucidate the effect of PAA-coated NP size on inhibitory capabilities. PAA-coated NPs exhibiting diameters of $8 \mathrm{~nm}, 18 \mathrm{~nm}$, and $40 \mathrm{~nm}$ were examined for their ability to attenuate $\mathrm{A} \beta_{1-40}$ aggregation. These NP sizes were selected to 
span the range of sizes able to cross the blood-brain barrier and undergo clearance from the body $[57,58]$. Similar to the inhibition observed in the presence of $18 \mathrm{~nm}$ PAA-coated NPs, the smaller $8 \mathrm{~nm}$ NPs reduced the equilibrium plateau by $>90 \%$ at concentrations as low as $20 \mathrm{pM}$ (Fig. 5, Table 1), demonstrating their effectiveness as $\mathrm{A} \beta$ aggregation inhibitors. This result was corroborated by the absence of aggregate material observed via TEM (Fig. 4f). In contrast, $40 \mathrm{~nm}$ PAAcoated NPs were ineffective at preventing the formation of $A \beta_{1-40}$ aggregates. Although these NPs quenched ThT fluorescence (Fig. 2), precluding their assessment via ThT, their inability to prevent aggregate formation was evidenced by TEM images displaying a similar quantity of aggregate material (Fig. 4h) compared to the control of equivalent magnification (Fig. 4d). These results demonstrate that only smaller PAA-coated NPs are capable of serving as effective inhibitors of $A \beta_{1-40}$ aggregation. This observation is in agreement with other studies reporting variations in inhibition of amyloid protein aggregation by NPs exhibiting different sizes [21, 28]. As in the current study, larger NPs are consistently less effective inhibitors, suggesting that high NP curvature may be needed to impart inhibitory capabilities.

Both $8 \mathrm{~nm}$ and $18 \mathrm{~nm}$ PAA-coated nanospheres were capable of abrogating $A \beta$ aggregation at a substoichiometric ratio of 1:2,000,000. While other studies have proposed NP-protein binding as the mode of aggregation inhibition, this extremely low NP to monomer ratio suggests that these surface-coated NPs are acting via another mechanism. Moreover, TEM images show that NPs did

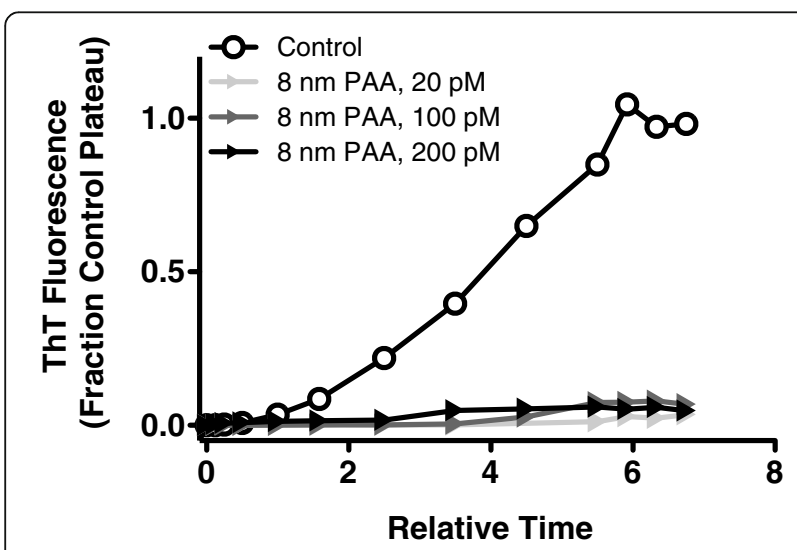

Fig. 5 Effect of $8 \mathrm{~nm}$ PAA-coated gold NPs on $A \beta_{1-40}$ monomer aggregation. $A \beta_{1-40}$ monomer diluted to $40 \mu \mathrm{M}$ in $40 \mathrm{mM}$ Tris- $\mathrm{HCl}$ $(\mathrm{pH}$ 8.0) was aggregated alone (control, $\mathrm{O}$ ) or in the presence of $8 \mathrm{~nm}$ PAA-coated NPs at concentrations of $200 \mathrm{pM}(\mathbf{\vee}), 100 \mathrm{pM}(>)$ ), or $20 \mathrm{pM}($ ). Monomer aggregation was induced by continuous agitation and monitored periodically via ThT fluorescence. ThT fluorescence and time values are presented as in Fig. 3. Results are representative of 3 independent experiments not co-localize with aggregates and that morphological changes were not isolated to regions near NPs. A similar lack of interaction with aggregated protein is also reported for other NP types [20,50, 54, 59]. These observations suggest a dynamic interaction between NP-localized protein and the bulk solution.

\section{Theoretical calculations indicate that surface charged NPs alter local solution conditions that can influence $A \beta$ aggregation}

The strikingly low stoichiometry at which inhibition of $\mathrm{A} \beta_{1-40}$ aggregation by PAA-coated NPs was observed as well as the lack of association between NPs and A $\beta$ aggregates within TEM images suggest that interactions other than sequestration of $A \beta_{1-40}$ monomer at the NP surface may play a role in the inhibitory capabilities of surface-coated NPs. A potential mechanism that can account for these congruent observations exists in the effect that the curved, charged NP surface has upon local solution conditions, including $\mathrm{pH}$ and ionic strength [21], both of which significantly influence $A \beta$ aggregation [60-62]. Specifically, $A \beta$ aggregation is attenuated in the presence of acidic and basic $\mathrm{pH}[61,63-65]$, while aggregation is promoted by the presence of a higher ionic strength, or charge density [62, 66-70]. Moreover, both solution $\mathrm{pH}[60,65,66,71]$ and ionic strength $[66$, $67,70]$ can modulate aggregate morphology. To explore this possibility, a self-consistent molecular field theory (SCMFT) was developed and implemented to describe molecular organization near the curved, charged NP surface. Theoretical calculation of the equilibrium concentrations of solution species allowed for the determination of local solution $\mathrm{pH}$ and charge density.

Theoretical calculations demonstrate pronounced changes in solution $\mathrm{pH}$ and solution charge density near the surface of $18 \mathrm{~nm}$ NPs suspended in $40 \mathrm{mM}$ Tris- $\mathrm{HCl}$ (pH 8.0) (Fig. 6). Cationic NP surfaces induce an elevated local solution $\mathrm{pH}$ and a negative charge density, while anionic NP surfaces depress the local solution $\mathrm{pH}$ and induce a positive solution charge density. These changes result from the system localizing counterions near the NP surface to balance the NP surface charge. The magnitude of NP-induced alterations is consistent with conditions under which altered $A \beta$ aggregation would occur [37, 61, 62]. Moreover, a greater absolute magnitude of surface charge produces more pronounced changes in the local solution molecular organization, leading to larger deviations from the bulk solution. This observation is congruent with prior experimental reports in which NPs with a higher absolute magnitude of surface charge imparted greater inhibition $[22,25]$. For NPs with a large magnitude of surface charge, these effects extend several nanometers beyond the NP surface. This spatial pervasiveness 

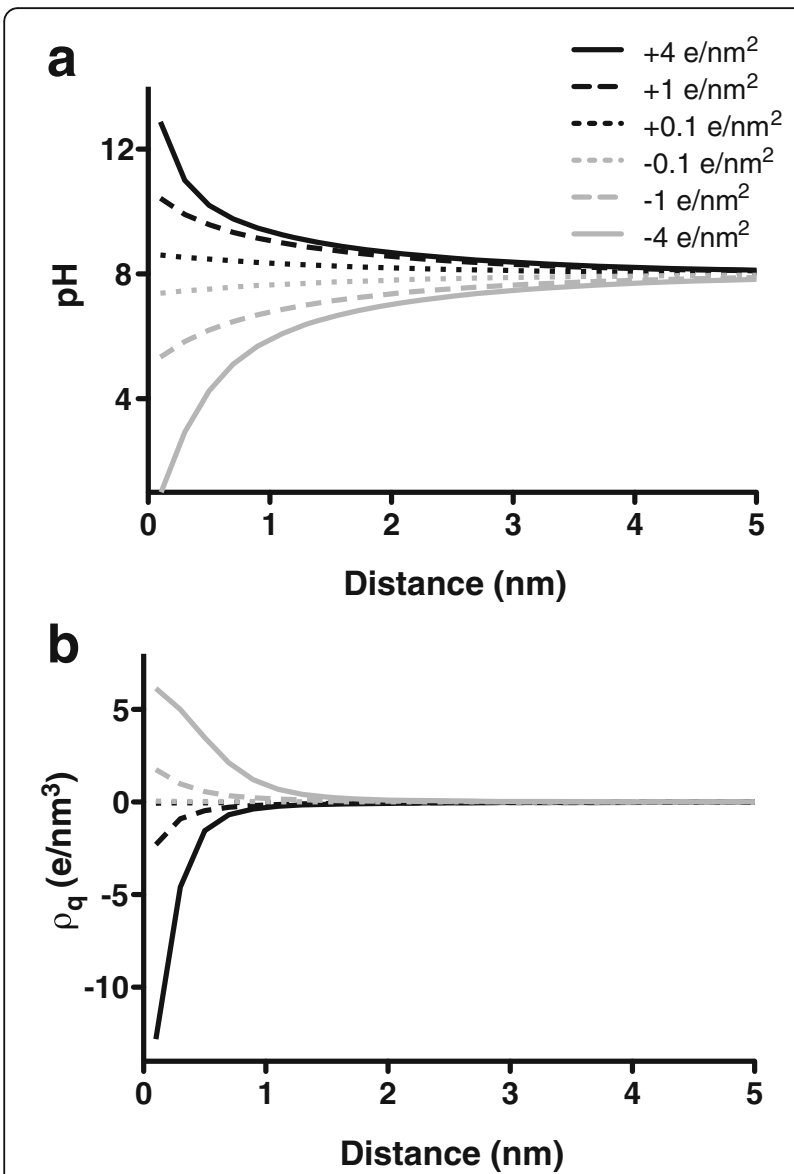

Fig. 6 Effect of NP surface charge on local solution $\mathrm{pH}$ and charge density. The equilibrium molecular organization near the surface of NPs was modeled using a SCMFT incorporating water, hydronium, hydroxide, chloride, and Tris. Theoretical calculations were performed for $18 \mathrm{~nm}$ NPs in the presence of $40 \mathrm{mM}$ Tris- $\mathrm{HCl}$ (pH 8.0) for NPs exhibiting a positive (black lines) or negative (grey lines) surface charge with absolute surface charge $\left(\sigma_{q}\right)$ magnitudes of $4 \mathrm{e} / \mathrm{nm}^{2}$ (solid lines), $1 \mathrm{e} / \mathrm{nm}^{2}$ (dashed lines), or $0.1 \mathrm{e} / \mathrm{nm}^{2}$ (dotted lines). Local solution $\mathrm{pH}$ (panel $\mathbf{a}$ ) and charge density $\left(\rho_{\mathrm{q}}\right)$ (panel b) are plotted as a function of distance from the NP surface

would allow protein to exchange between local and bulk solution conditions. Such exchange may impede the formation of organized amyloid structures or disrupt those structures formed within the bulk solution. Previous observations support such a dynamic exchange $[25,59,72]$ along with the dominance of nanoscale surface properties over the bulk solution [16], which may be partly due to the persistence of protein structures formed near the NP surface [72].

Interestingly, an asymmetry exists about the bulk solution values, with cationic NPs eliciting a more pronounced change in charge density. This asymmetry is a manifestation of differences between counterions that become localized to balance the NP surface charge. The cationic NP surface draws hydroxide and chloride to its surface, with chloride being the predominant species, while the anionic
NP surface draws hydronium and Tris to its surface, with Tris predominating. In the latter case, because Tris is in chemical equilibrium with its local environment through the acid dissociation reaction $\left(t r^{+} \rightleftarrows t r+H^{+}\right)$, the fraction of Tris that is charged, and hence capable of balancing the anionic NP surface charge, is interdependent upon the local $\mathrm{pH}$ environment, thus causing a distinct effect upon molecular organization. This asymmetric magnitude in charge density combined with the opposing changes in both local solution $\mathrm{pH}$ and charge density induced by anionic vs. cationic NPs may contribute to the distinct inhibitory effects observed for anionic and cationic NPs, including the stronger inhibitory capabilities of anionic NPs and the ability of cationic, but not anionic, NPs to alter aggregate morphology. Moreover, polymeric PAA can produce steric hindrance that results in a preference for localizing protons over bulky ions, such as Tris. The result is a more pronounced effect on the local pH compared to citrate, congruent with the enhanced effectiveness of PAA-coated vs. citrate-coated NPs.

Overall, theoretical results parallel experimental observations in both the current and prior studies, supporting the hypothesis that inhibition of amyloid aggregation may stem, in part, from NP-induced changes in local solution conditions.

\section{Conclusion}

This study provides evidence that electric charge, surface chemistry, and size can modulate the ability of gold nanospheres to inhibit $A \beta$ aggregation. NP surface chemistry and size influence the extent of inhibition, while electric charge defines NP ability to alter aggregate morphology. Overall, PAA-coated NPs $18 \mathrm{~nm}$ and smaller are superior inhibitors, abrogating aggregation at substoichiometric ratios as low as $1: 2,000,000$ with $A \beta$. Such low stoichiometric ratios coupled with the lack of NP-aggregate association prompted investigation for NP-induced changes in local solution conditions to influence aggregation. A theoretical model describing changes in local solution $\mathrm{pH}$ and charge density displays congruencies with experimental observations to support this potential mechanism. Cell viability assays further demonstrated that the most effective NP inhibitors are non-toxic. Together, these findings identify surface-coated gold nanospheres as potential tunable therapeutic agents for the inhibition of $A \beta$ aggregation and provide insight into the physiochemical properties of effective NP inhibitors.

\section{Methods}

Materials

$\mathrm{A} \beta_{1-40}$ was purchased from AnaSpec, Inc. (San Jose, CA). Gold (III) trichloride hydrate $\mathrm{HAuCl}_{4} \cdot 3 \mathrm{H}_{2} \mathrm{O}$, trisodium citrate, sodium borohydride $\left(\mathrm{NaBH}_{4}\right)$, ascorbic acid, 
CTAB, ThT, Triton-X 100, XTT, and all cell culture media and reagents were purchased from Sigma-Aldrich (St. Louis, MO). The polyelectrolytes PAH and PAA were also obtained from Sigma-Aldrich and used without further purification. Sodium chloride $(\mathrm{NaCl})$ was purchased from Fisher Scientific. Uranyl acetate was purchased from Electron Microscopy Sciences (Hatfield, PA).

\section{Surface-coated gold NP synthesis and characterization}

Surface-coated gold NPs of average core diameters $8 \mathrm{~nm}, 18 \mathrm{~nm}$, and $40 \mathrm{~nm}$ were synthesized using a previously reported seeded growth method [73], described in detail within Additional file 1. NPs in their citratecapped form were either used for experimentation, coated with CTAB, which forms a bilayer on the surface causing the trimethylammonuim headgroup to face the aqueous solvent, or electrostatically over-coated in a layer-by-layer fashion with PAA and PAH [74]. Therefore, at $\mathrm{pH} 7$, the nanomaterials would present either a cationic (CTAB and $\mathrm{PAH}$ ) or anionic (citrate and PAA) surface. NPs were characterized using TEM and UV-vis absorbance spectroscopy.

\section{Toxicity of surface-coated gold NPs}

Potential toxicity of surface-coated NPs was probed in human neuroblastoma SH-SY5Y cells (American Type Culture Collection, Manassus, VA). Cellular reduction of XTT was employed to evaluate cellular metabolic activity following NP exposure. Cells, sustained and prepared for experiments as described in Additional file 1, were incubated $(24 \mathrm{~h})$ with NPs $(100 \mathrm{pM}$ or $200 \mathrm{pM})$ diluted into medium, with medium alone (negative control), or with $2 \%$ Triton-X 100 in medium (positive control). Following incubation, cells were washed and treated $(24 \mathrm{~h})$ with $0.33 \mathrm{mg} / \mathrm{mL} \mathrm{XTT} \mathrm{and} 8.3 \mu \mathrm{mol} / \mathrm{L}$ phenozene methyl sulfate. Metabolically active cells reduce XTT to an orange formazan product, for which absorbance $(450 \mathrm{~nm})$ was measured using a BioTek Synergy $2 \mathrm{mi}-$ croplate reader (Winooski, VT). Results are reported as a percentage of the negative control following background (medium containing XTT) subtraction.

\section{$A \beta_{1-40}$ monomer aggregation}

$A \beta_{1-40}$ monomer aggregation assays were performed similar to previously described methods [75]. Briefly, $A \beta_{1-40}$ monomer, purified via size exclusion chromatography (SEC) as described in Additional file 1, was diluted to $40 \mu \mathrm{M}$ in $40 \mathrm{mM}$ Tris $-\mathrm{HCl}$ (pH 8.0) and agitated (vortex, $800 \mathrm{rpm}, 25^{\circ} \mathrm{C}$ ) alone (control) or with 20-200 pM NPs. Periodically, a $20 \mu \mathrm{L}$ aliquot was removed and combined with $140 \mu \mathrm{L}$ of $10 \mu \mathrm{M}$ ThT, an amyloid-binding dye that yields a shifted, enhanced florescence upon recognition of the characteristic $\beta$-sheet structure of fibrillar $A \beta$ aggregates. Fluorescence $($ excitation $=450 \mathrm{~nm}$, emission $=470$ -
$500 \mathrm{~nm}$ ) was evaluated using a Perkin-Elmer LS-45 luminescence spectrometer (Waltham, MA). Fluorescence values were calculated as the integrated area under the emission curve with baseline (ThT alone) subtraction and plotted vs. aggregation time.

\section{ThT detection of $A \beta_{1-40}$ aggregates in the presence of surface-coated gold NPs}

To ensure that NPs do not compromise ThT detection, ThT fluorescence was evaluated for $5 \mu \mathrm{M} A \beta_{1-40}$ preformed fibrils, prepared as described in Additional file 1, in the presence of $8.75 \mu \mathrm{M}$ ThT and 5-200 pM NPs (concentrations congruent with those of diluted samples used to monitor aggregation). ThT fluorescence was measured after $2 \mathrm{~h}$ incubation. Compromised ThT detection was evaluated as a decrease in ThT fluorescence relative to that observed for fibrils in the absence of NPs and expressed as the fraction of ThT fluorescence observed for the control.

\section{Morphological evaluation of $A \beta_{1-40}$ aggregates}

To evaluate $A \beta_{1-40}$ aggregate morphology, monomer aggregation reactions were prepared for TEM following the time point at which the control reaction reached equilibrium (assessed via ThT). As described previously [75], a $10 \mu \mathrm{L}$ sample was placed on a 300 mesh formvarcarbon supported copper grid (Electron Microscopy Sciences, Hatfield, PA). After 3 min, the sample was wicked away from the bottom side of the grid using filter paper. Sample application was repeated twice, and grids were allowed to air dry $(24 \mathrm{~h})$. Gridded samples were stained (10 min) with $2 \%$ aqueous uranyl acetate, excess stain was wicked away, and grids were allowed to dry $(24 \mathrm{~h})$. Imaging was performed using a JEOL $200 \mathrm{CX}$ TEM (Tokyo, Japan) with an accelerating voltage of $120 \mathrm{kV}$. Blinded observation of samples with random selection of grid areas was implemented to reduce bias.

\section{Statistical analysis}

Using GraphPad Prism 5 software (San Diego, CA), the effect of NPs on aggregation was evaluated using a one-way analysis of variance (ANOVA) with Dunnett's post-test, and the effect of NPs on ThT detection was evaluated using a two-way ANOVA with Bonferroni posttest. $p<0.05$ was considered significant.

\section{Thermodynamic model}

A SCMFT was developed and parameterized to model the equilibrium molecular organization near the interface of surface-coated NPs suspended in $40 \mathrm{mM}$ Tris- $\mathrm{HCl}$ (pH 8.0). The NP surface was modeled as a sphere bearing a fixed surface charge where spherical symmetry was imposed. Five mobile species (water, hydronium, hydroxide, chloride, and Tris) were accounted for explicitly to 
capture the solvent environment. The chemical equilibrium of Tris is integrated into the model and made dependent upon the local solvent environment. The concentration of chloride was parameterized to achieve electroneutrality within the bulk solution. The SCMFT is expressed mathematically as a dimensionless free energy functional. The equilibrium molecular organization is determined through the minimization of this functional. Further details can be found in Additional file 1. This model was used to predict the molecular organization near the NP surface, from which the $\mathrm{pH}$ and charge density were determined a function of distance from the NP surface. Calculations were performed for $18 \mathrm{~nm}$ NPs with surface charges ranging from 4 to $-4 \mathrm{e} / \mathrm{nm}^{2}$.

\section{Additional file}

Additional file 1: Supporting Information. (DOCX $42 \mathrm{~kb}$ )

\section{Abbreviations}

AD: Alzheimer's disease; ANOVA: Analysis of variance; $A \beta$ : Amyloid- $\beta$ protein; BSA: Bovine serum albumin; CTAB: Cetyltrimethylammonium bromide; NP: Nanoparticle; PAA: Poly(acrylic acid); PAH: Poly(allylamine)hydrochloride; SCMFT: Self-consistent molecular field theory; SEC: Size exclusion chromatography; TEM: Transmission electron microscopy; ThT: Thioflavin T; XTT: 2,3-bis(2-methoxy-4-nitro-5-sulfophenyl)-2H-tetrazolium-5-carboxanilide

\section{Acknowledgements}

Not applicable.

\section{Funding}

This work was supported by the National Science Foundation's Research at Undergraduate Institutions Program (RUI, CHE-0701406 to R.M., C.J.M., and M.A.M.) and the Faculty Early Career Development Program (CAREER, CBET0644826 to M.A.M.).

\section{Availability of data and materials}

The datasets acquired and analyzed during the current study are available from the corresponding author on reasonable request.

\section{Authors' contributions}

KAM, DDS-O, RM, CJM, and MAM designed the study. SL, KSJ, VDL, LJ, NG, VMN, and SM synthesized and characterized the surface-coated gold NPs. KAM, DDS$\mathrm{O}, \mathrm{ML}$, and KSJ characterized inhibitory properties of the surface-coated gold NPs. KP performed studies to determine toxicity of the surface-coated gold NPs. NvdM and MJU conceptualized and implemented the theoretical model. KAM, $K P$, and MAM wrote the manuscript. MU, RM, CJM, and MAM supervised various aspects of the project. All authors read and approved the final manuscript.

\section{Competing interests}

The authors declare that they have no competing interests.

\section{Consent for publication}

Not applicable.

\section{Ethics approval and consent to participate}

Not applicable.

\section{Author details}

'Biomedical Engineering Program, University of South Carolina, Columbia, SC 29208, USA. ${ }^{2}$ Department of Chemical Engineering, University of South Carolina, 2C02 Swearingen Engineering Center, Columbia, SC 29208, USA. ${ }^{3}$ Department of Biological Sciences, University of South Carolina, Columbia, SC 29208, USA. ${ }^{4}$ Department of Biological and Physical Sciences, South
Carolina State University, Orangeburg, SC 29117, USA. ${ }^{5}$ Department of Chemistry, University of Illinois at Urbana-Champaign, Urbana, IL 61801, USA.

Received: 15 August 2016 Accepted: 3 January 2017

Published online: 06 February 2017

\section{References}

1. Alzheimer A. Uber eine eigenartige Erkrankung der Hirnrinde. Allg Zeits Psychi- atry Psych Med. 1907;64:146-8.

2. Hardy JA, Higgins GA. Alzheimer's disease: the amyloid cascade hypothesis. Science. 1992;256:184-5.

3. Hardy J, Selkoe DJ. The amyloid hypothesis of Alzheimer's disease: progress and problems on the road to therapeutics. Science. 2002;297:353-6.

4. Lorenzo A, Yankner BA. $\beta$-amyloid neurotoxicity requires fibril formation and is inhibited by congo red. Proc Natl Acad Sci U S A. 1994; 91(December): 12243-7.

5. Barghorn S, Nimmrich V, Striebinger A, Krantz G, Keller P, Janson B, Bahr M, Schmidt M, Bitner RS, Harlan J, Barlow E, Ebert U, Hillen H. Globular amyloid $\beta$-peptide1-42 oligomer - A homogenous and stable neuropathological protein in Alzheimer's disease. J Neurochem. 2005:95:834-47.

6. Chen QS, Kagan BL, Hirakura Y, Xie CW. Impairment of hippocampal long-term potentiation by Alzheimer amyloid $\beta$-peptides. J Neurosci Res. 2000;60:65-72.

7. Nomura I, Kato N, Kita T, Takechi H. Mechanism of impairment of long-term potentiation by amyloid $\beta$ is independent of NMDA receptors or voltagedependent calcium channels in hippocampal CA1 pyramidal neurons. Neurosci Lett. 2005;391:1-6.

8. Shankar GM, Bloodgood BL, Townsend M, Walsh DM, Selkoe DJ, Sabatini BL. Natural oligomers of the Alzheimer amyloid- $\beta$ protein induce reversible synapse loss by modulating an NMDA-type glutamate receptor-dependent signaling pathway. J Neurosci. 2007;27:2866-75.

9. Cleary JP, Walsh DM, Hofmeister JJ, Shankar GM, Kuskowski MA, Selkoe DJ, Ashe $\mathrm{KH}$. Natural oligomers of the amyloid- $\beta$ protein specifically disrupt cognitive function. Nat Neurosci. 2005;8:79-84.

10. Gao J, Gu H, Xu B. Multifunctional magnetic nanoparticles: design, synthesis, and biomedical applications. Acc Chem Res. 2009:42:1097-107.

11. Cormode DP, Skajaa T, Fayad ZA, Mulder WJM. Nanotechnology in medical imaging: probe design and applications. Arterioscler Thromb Vasc Biol. 2009;29:992-1000

12. Faraji AH, Wipf P. Nanoparticles in cellular drug delivery. Bioorganic Med Chem. 2009:17:2950-62.

13. Tong S, Fine EJ, Lin Y, Cradick TJ, Bao G. Nanomedicine: Tiny particles and machines give huge gains. Ann Biomed Eng. 2014;42:243-59.

14. Tonga GY, Saha K, Rotello VM. 25th anniversary article: Interfacing nanoparticles and biology: New strategies for biomedicine. Adv Mater. 2014:26:359-70.

15. Wang C, Zhang M, Mao X, Yu Y, Wang CX, Yang YL. Nanomaterials for reducing amyloid cytotoxicity. Adv Mater. 2013;25:3780-801.

16. Mahmoudi M, Kalhor HR, Laurent S, Lynch I. Protein fibrillation and nanoparticle interactions: opportunities and challenges. Nanoscale. 2013;5: 2570-88.

17. Fei $L$, Perrett $S$. Effect of Nanoparticles on Protein Folding and Fibrillogenesis. Int J Mol Sci. 2009;10:646-55.

18. Zaman M, Ahmad E, Qadeer A, Rabbani G, Khan RH. Nanoparticles in relation to peptide and protein aggregation. Int J Nanomedicine. 2014:9:899-912.

19. Busquets MA, Sabaté R, Estelrich J. Potential applications of magnetic particles to detect and treat Alzheimer's disease. Nanoscale Res Lett. 2014;9:538.

20. Liao YH, Chang YJ, Yoshiike Y, Chang YC, Chen YR. Negatively charged gold nanoparticles inhibit Alzheimer's amyloid- $\beta$ fibrillization, induce fibril dissociation, and mitigate neurotoxicity. Small. 2012;8:3631-9.

21. Mahmoudi M, Quinlan-Pluck F, Monopoli MP, Sheibani S, Vali H, Dawson KA Lynch I. Influence of the physiochemical properties of superparamagnetic iron oxide nanoparticles on amyloid $\beta$ protein fibrillation in solution. ACS Chem Neurosci. 2013;4:475-85.

22. Saraiva AM, Cardoso I, Saraiva MJ, Tauer K, Pereira MC, Coelho MAN Möhwald H, Brezesinski G. Randomization of amyloid- $\beta$-peptide(1-42) conformation by sulfonated and sulfated nanoparticles reduces aggregation and cytotoxicity. Macromol Biosci. 2010;10:1152-63. 
23. Saraiva AM, Cardoso I, Pereira MC, Coelho MAN, Saraiva MJ, Möhwald H, Brezesinski G. Controlling amyloid- $\beta$ peptide(1-42) oligomerization and toxicity by fluorinated nanoparticles. ChemBioChem. 2010;11:1905-13.

24. Cabaleiro-Lago C, Quinlan-Pluck F, Lynch I, Dawson KA, Linse S. Dual effect of amino modified polystyrene nanoparticles on amyloid $\beta$ protein fibrillation. ACS Chem Neurosci. 2010;1:279-87.

25. Rocha S, Thünemann AF, Pereira MDC, Coelho M, Möhwald H, Brezesinski G. Influence of fluorinated and hydrogenated nanoparticles on the structure and fibrillogenesis of amyloid beta-peptide. Biophys Chem. 2008;137:35-42.

26. Yoo SI, Yang M, Brender JR, Subramanian V, Sun K, Joo NE, Jeong SH, Ramamoorthy A, Kotov NA. Inhibition of amyloid peptide fibrillation by inorganic nanoparticles: Functional similarities with proteins. Angew Chemie - Int Ed. 2011;50:5110-5.

27. Cabaleiro-Lago C, Quinlan-Pluck F, Lynch I, Lindman S, Minogue AM, Thulin E, Walsh DM, Dawson KA, Linse S. Inhibition of amyloid $\beta$ protein fibrillation by polymeric nanoparticles. J Am Chem Soc. 2008;130:15437-43.

28. Mirsadeghi S, Shanehsazzadeh S, Atyabi F, Dinarvand R. Effect of PEGylated superparamagnetic iron oxide nanoparticles (SPIONs) under magnetic field on amyloid beta fibrillation process. Mater Sci Eng C. 2016;59:390-7.

29. Doig AJ. Peptide inhibitors of beta-amyloid aggregation. Curr Opin Drug Discov Devel. 2007;10:533-9.

30. Re F, Airoldi C, Zona C, Masserini M, La Ferla B, Quattrocchi N, Nicotra F. Beta amyloid aggregation inhibitors: small molecules as candidate drugs for therapy of Alzheimer's disease. Curr Med Chem. 2010;17:2990-3006.

31. $M a$ Q, Wei $G$, Yang X. Influence of Au nanoparticles on the aggregation of amyloid- $\beta-(25-35)$ peptides. Nanoscale. 2013;5:10397-403.

32. Ghavami M, Rezaei M, Ejtehadi R, Lotfi M, Shokrgozar MA, Abd Emamy B, Raush J, Mahmoudi M. Physiological temperature has a crucial role in amyloid beta in the absence and presence of hydrophobic and hydrophilic nanoparticles. ACS Chem Neurosci. 2013;4:375-8.

33. Wu W-H, Sun X, Yu Y-P, Hu J, Zhao L, Liu Q, Zhao Y-F, Li Y-M. TiO nanoparticles promote $\beta$-amyloid fibrillation in vitro. Biochem Biophys Res Commun. 2008;373:315-8.

34. Murphy CJ, Gole AM, Stone JW, Sisco PN, Alkilany AM, Goldsmith EC, Baxter SC. Gold nanoparticles in biology: Beyond toxicity to cellular imaging. Acc Chem Res. 2008:41:1721-30.

35. Tiwari PM, Vig K, Dennis VA, Singh SR. Functionalized Gold Nanoparticles and Their Biomedical Applications. Nanomaterials. 2011;1:31-63.

36. Wang Z, Ma L. Gold nanoparticle probes. Coord Chem Rev. 2009;253:1607-18.

37. Uskoković $V$. Entering the era of nanoscience: Time to be so small. J Biomed Nanotechnol. 2013;9:1441-70.

38. Alkilany AM, Lohse SE, Murphy CJ. The gold standard: Gold nanoparticle libraries to understand the nano-bio interface. Acc Chem Res. 2013;46:650-61.

39. Wan J, Wang JH, Liu T, Xie Z, Yu XF, Li W. Surface chemistry but not aspect ratio mediates the biological toxicity of gold nanorods in vitro and in vivo. Sci Rep. 2015:5:11398.

40. Tarantola M, Pietuch A, Schneider D, Rother J, Sunnick E, Rosman C, Pierrat S, Sönnichsen C, Wegener J, Janshoff A. Toxicity of gold-nanoparticles: synergistic effects of shape and surface functionalization on micromotility of epithelial cells. Nanotoxicology. 2011;5:254-68.

41. Alkilany AM, Nagaria PK, Hexel CR, Shaw TJ, Murphy CJ, Wyatt MD. Cellular uptake and cytotoxicity of gold nanorods: Molecular origin of cytotoxicity and surface effects. Small. 2009;5:701-8.

42. Yao M, He L, McClements DJ, Xiao H. Uptake of gold nanoparticles by intestinal epithelial cells: impact of particle size on their absorption, accumulation, and toxicity. J Agric Food Chem. 2015;63:8044-9.

43. Rosário F, Hoet P, Santos C, Oliveira H. Death and cell cycle progression are differently conditioned by the AgNP size in osteoblast-like cells. Toxicology. 2016:368:103-15

44. Lakowicz JR. Radiative decay engineering 5: Metal-enhanced fluorescence and plasmon emission. Anal Biochem. 2005;337:171-94.

45. Hudson SA, Ecroyd H, Kee TW, Carver JA. The thioflavin T fluorescence assay for amyloid fibril detection can be biased by the presence of exogenous compounds. FEBS J. 2009;276:5960-72.

46. Moss MA, Varvel NH, Nichols MR, Reed DK, Rosenberry TL. Nordihydroguaiaretic acid does not disaggregate $\beta$-amyloid(1-40) protofibrils but does inhibit growth arising from direct protofibril association. Mol Pharmacol. 2004;66:592-600.

47. Gandy $S$. The role of cerebral amyloid $\beta$ accumulation in common forms of Alzheimer disease. J Clin Invest. 2005;115:1121-9.
48. Guntert A, Dobeli H, Bohrmann B. High sensitivity analysis of amyloid-beta peptide composition in amyloid deposits from human and PS2APP mouse brain. Neuroscience. 2006;143:461-75.

49. Cabaleiro-Lago C, Szczepankiewicz O, Linse S. The effect of nanoparticles on amyloid aggregation depends on the protein stability and intrinsic aggregation rate. Langmuir. 2012;28:1852-7.

50. Hadas S, Georges B, Shlomo M. Synthesis and characterization of fluorinated magnetic core-shell nanoparticles for inhibition of insulin amyloid fibril formation. Nanotechnology. 2009;20:225106.

51. Bellova A, Bystrenova E, Koneracka M, Kopcansky P, Valle F, Tomasovicova N, Timko M, Bagelova J, Biscarini F, Gazova Z. Effect of $\mathrm{Fe}_{3} \mathrm{O}_{4}$ magnetic nanoparticles on lysozyme amyloid aggregation. Nanotechnology. 2010;21:65103.

52. Sardar S, Pal S, Maity S, Chakraborty J, Halder UC. Amyloid fibril formation by $\beta$-lactoglobulin is inhibited by gold nanoparticles. Int J Biol Macromol. 2014;69C:137-45.

53. Sen S, Konar S, Pathak A, Dasgupta S, DasGupta S. Effect of functionalized magnetic MnFe2O4 nanoparticles on fibrillation of human serum albumin. J Phys Chem B. 2014;118:11667-76.

54. Naik A, Kambli P, Borana M, Mohanpuria N, Ahmad B, Kelkar-Mane V, Ladiwala U. Attenuation of lysozyme amyloid cytotoxicity by SPIONmediated modulation of amyloid aggregation. Int J Biol Macromol. 2015;74:439-46.

55. Hsieh S, Chang CW, Chou HH. Gold nanoparticles as amyloid-like fibrillogenesis inhibitors. Colloids Surfaces B Biointerfaces. 2013;112: $525-9$

56. Jans $H$, Jans K, Lagae L, Borghs G, Maes G, Huo Q. Poly(acrylic acid)stabilized colloidal gold nanoparticles: synthesis and properties. Nanotechnology. 2010;21:455702

57. Choi HS, Liu W, Misra P, Tanaka E, Zimmer JP, Itty Ipe B, Bawendi MG, Frangioni JV. Renal clearance of quantum dots. Nat Biotechnol. 2007;25:1165-70.

58. Koffie RM, Farrar CT, Saidi L-J, William CM, Hyman BT, Spires-Jones TL. Nanoparticles enhance brain delivery of blood-brain barrier-impermeable probes for in vivo optical and magnetic resonance imaging. Proc Natl Acad Sci. 2011;108:18837-42.

59. Linse S, Cabaleiro-Lago C, Xue W-F, Lynch I, Lindman S, Thulin E, Radford SE, Dawson KA. Nucleation of protein fibrillation by nanoparticles. Proc Nat Acad Sci U S A. 2007:104:8691-6.

60. Wood SJ, Maleeff B, Hart T, Wetzel R. Physical, morphological and functional differences between $\mathrm{pH} 5.8$ and 7.4 aggregates of the Alzheimer's amyloid peptide Aß. J Mol Biol. 1996;256:870-7.

61. Kobayashi S, Tanaka Y, Kiyono M, Chino M, Chikuma T, Hoshi K, Ikeshima H. Dependence $\mathrm{pH}$ and proposed mechanism for aggregation of Alzheimer's disease-related amyloid- $\beta$ (1-42) protein. J Mol Struct. 2015;1094:109-17.

62. Snyder SW, Ladror US, Wade WS, Wang GT, Barrett LW, Matayoshi ED, Huffaker HJ, Krafft GA, Holzman TF. Amyloid-beta aggregation: selective inhibition of aggregation in mixtures of amyloid with different chain lengths. Biophys J. 1994;67:1216-28.

63. Serpell LC. Alzheimer's amyloid fibrils: structure and assembly. Biochim Biophys Acta - Mol Basis Dis. 2000;1502:16-30.

64. Barrow CJ, Yasuda A, Kenny PTM, Zagorski MG. Solution conformations and aggregational properties of synthetic amyloid $\beta$-peptides of Alzheimer's disease. Analysis of circular dichroism spectra. J Mol Biol. 1992;225:1075-93.

65. Fraser PE, Nguyen JT, Surewicz WK, Kirschner DA. pH-dependent structural transitions of Alzheimer amyloid peptides. Biophys J. 1991;60:1190-201.

66. Stine WB, Dahlgren KN, Krafft GA, LaDu MJ. In vitro characterization of conditions for amyloid- $\beta$ peptide oligomerization and fibrillogenesis. J Biol Chem. 2003;278:11612-22.

67. Isaacs AM, Senn DB, Yuan M, Shine JP, Yankner BA. Acceleration of amyloid $\beta$-peptide aggregation by physiological concentrations of calcium. J Biol Chem. 2006;281:27916-23.

68. Hilbich C, Kisters-Woike B, Reed J, Masters CL, Beyreuther K. Aggregation and secondary structure of synthetic amyloid $\beta A 4$ peptides of Alzheimer's disease. J Mol Biol. 1991;218:149-63.

69. Johansson AS, Berglind-Dehlin F, Karlsson G, Edwards K, Gellerfors P, Lannfelt L. Physiochemical characterization of the Alzheimer's diseaserelated peptides A 1 1-42Arctic and A 1-42wt. FEBS J. 2006;273:2618-30.

70. Klement K, Wieligmann K, Meinhardt J, Hortschansky P, Richter W, Fändrich $M$. Effect of different salt ions on the propensity of aggregation and on the structure of Alzheimer's $A B(1-40)$ amyloid fibrils. J Mol Biol. 2007; $373: 1321-33$ 
71. Su Y, Chang PT. Acidic pH promotes the formation of toxic fibrils from B-amyloid peptide. Brain Res. 2001;893:287-91.

72. Giacomelli CE, Norde W. Influence of hydrophobic teflon particles on the structure of amyloid $\beta$-peptide. Biomacromolecules. 2003:4:1719-26.

73. Jana NR, Gearheart L, Murphy CJ. Seeding growth for size control of 5-40 nm diameter gold nanoparticles. Langmuir. 2001;17:6782-6.

74. Gole A, Murphy CJ. Polyelectrolyte-coated gold nanorods: Synthesis, characterization and immobilization. Chem Mater. 2005;17(c):1325-30

75. Davis TJ, Soto-Ortega DD, Kotarek JA, Gonzalez-Velasquez FJ, Sivakumar K, Wu L, Wang Q, Moss MA. Comparative study of inhibition at multiple stages of amyloid- $\beta$ self-assembly provides mechanistic insight. Mol Pharmacol. 2009;76:405-13.

Submit your next manuscript to BioMed Central and we will help you at every step:

- We accept pre-submission inquiries

- Our selector tool helps you to find the most relevant journal

- We provide round the clock customer support

- Convenient online submission

- Thorough peer review

- Inclusion in PubMed and all major indexing services

- Maximum visibility for your research

Submit your manuscript at www.biomedcentral.com/submit
Biomed Central 